\title{
A local risk map using field observations of the Asian longhorned beetle to optimize monitoring activities
}

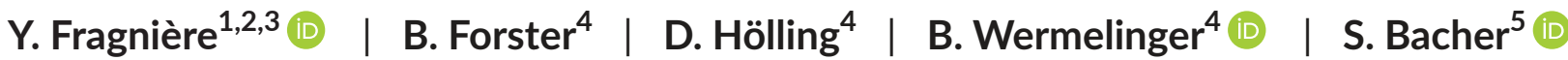

\begin{abstract}
${ }^{1}$ Forest and Fauna Service of the State of Fribourg, Givisiez, Switzerland

${ }^{2}$ Grangeneuve Agricultural Institute of the State of Fribourg, Posieux, Switzerland

${ }^{3}$ Natural History Museum Fribourg, Fribourg, Switzerland

${ }^{4}$ Swiss Federal Institute for Forest, Snow and Landscape Research WSL, Birmensdorf, Switzerland

${ }^{5}$ Department of Biology, Ecology\& Evolution Unit, University of Fribourg, Fribourg, Switzerland

\section{Correspondence}

Yann Fragnière, Forest and Fauna Service of the State of Fribourg, Givisiez, Switzerland. Email: yann.fragniere@fr.ch
\end{abstract}

\begin{abstract}
The Asian longhorned beetle Anoplophora glabripennis (Motschulsky) (Coleoptera: Cerambycidae) is one of the most dangerous xylophagous pests affecting broadleaf trees in the world. Eradication programmes are undertaken in non-native regions, requiring extensive resources and involving high costs. An adapted strategy must be set up to optimize the ratio cost/probability of success. We developed a method to generate a risk index of $A$. glabripennis presence at a local scale, in the surrounding area of an infestation, using field observations (counts of adult insects, exit holes and infested trees). The method, mathematically based on the bivariate symmetric Laplace distribution, has thus reasonable input requirements. The output risk map is easy to interpret and can be directly used by decision-makers. We used our approach in three infestations in Switzerland. The risk map represented well the insect pressure (beetle population density). We highlighted the fact that survey boundaries, commonly chosen using constant distances from the infestation, should be selected regarding the spatial distribution of the insect pressure, to prioritize monitoring activities. The risk map provides a helpful instrument for advanced survey planning after a first overview, for example to decide which area and which host trees should be inspected for infestations.
\end{abstract}

\section{KEYWORDS}

ALB, eradication strategy, model, risk index, survey, Switzerland

\section{1 | INTRODUCTION}

The Asian longhorned beetle (ALB) Anoplophora glabripennis (Motschulsky), a beetle of the Cerambycidae family, is native to Asia and occurs naturally in China and Korea (Lingafelter \& Hoebeke, 2002). This species was introduced accidentally into North America and Europe via solid wood packing material and threatens urban ornamental broadleaf trees and forests in areas where it has been introduced (Faccoli, Favaro, Smith, \& Wu, 2015; Hu, Angeli, Schuetz, Luo, \& Hajek, 2009; Javal et al., 2017; Nowak, Pasek, Sequeira, Crane, \& Mastro, 2001; Wermelinger et al., 2015). In Europe and North America, the ALB attacks healthy trees, principally maples (Acer spp.), buckeye and horse chestnuts (Aesculus spp.), willows (Salix spp.), elms (Ulmus spp.), birches (Betula spp.), plane trees (Platanus spp.) and poplars (Populus spp.) (hereafter termed "primary hosts"), although several other genera have been regionally reported as occasional hosts (hereafter termed "secondary hosts") (Haack, Hérard, Sun, \& Turgeon, 2010; Haack et al., 2006; Hérard et al., 2006; Meng, Hoover, \& Keena, 2015; Sawyer, 2003). Larvae boring inside tree trunks and branches can cause severe damage to the tree's vascular system and the wood's structural properties. This can lead to the death of the attacked trees (Cavey, Hoebeke, Passoa, \& Lingafelter, 1998; Hu et al., 2009).

For these reasons, the ALB is considered as a dangerous quarantine pest in Europe and North America and immediate eradication programmes must be undertaken when infestations are discovered (Forster \& Wermelinger, 2012; Hu et al., 2009; MacLeod, Evans, \& Baker, 2002; Pluess et al., 2013; USDA, 2016; Van Der Gaag et al., 2010). Control strategies in Europe follow the EPPO standards on 
phytosanitary measures (EPPO, 2016) and consist in integrated approaches. In practice, the detailed measures may sometimes vary by regions and countries, but generally have to lead to eradication, if feasible. Early detection is crucial because the chance of successful eradication is higher in small infested areas (Pluess et al., 2012). When a first adult ALB or an attacked tree is discovered, a survey is necessary to check for symptoms in the surrounding trees. The subsequent eradication measures involve removal and destruction of all infested trees and capture of adult beetles. Preventive measures must be taken to avoid human-mediated dispersal (e.g., by wooden packaging material, firewood or tree trimming material) and information and education of the residents can help to reinforce the survey. Finally, careful monitoring must be undertaken to evaluate the efficacy of the eradication measures and to detect new infested trees. Usually, 4 years of negative surveys are required to declare successful eradication (Pluess et al., 2013; USDA, United States Department of Agriculture, 2016).

Surveys are carried out by visual inspection of trees for exit holes, frass or oviposition sites, often requiring tree climbers or bucket trucks. Often also, trained detection dogs are used (Hoyer-Tomiczek \& Sauseng, 2013). The resulting costs of careful monitoring are very high, and there is never a $100 \%$ guarantee of eradication success: the area that can be surveyed is limited, not every broadleaf tree can be systematically controlled and visual surveys are not infallible. The U.S. Department of Agriculture's Animal and Plant Health Inspection Service (APHIS) estimated visual surveys to be only $30 \%-66 \%$ efficient in the United States (Milius, 1999; Smith, Turgeon, De Groot, \& Gasman, 2009). Surveys have to be repeated to find possible signs of developing larvae in the trees. Consequently, a monitoring strategy should try to minimize the ratio cost/chances of success. Mathematical models can provide a very powerful tool to help in decision-making. Models have been integrated as a key component in eradication of the ALB by the regulatory agencies in the United States, Canada and Europe (Smith et al., 2009).

Many researchers have already developed different kinds of models, to describe ALB dispersal rate, population spread, individual daily movements and infestation risk in different contexts (Bancroft \& Smith, 2001; Favaro, Wichmann, Ravn, \& Faccoli, 2015; Fournier \& Turgeon, 2017; Gourley \& Lou, 2014; Gourley \& Zou, 2011; Lethmayer, 2013; Lu \& Russell, 2005; Manoukis, Hall, \& Geib, 2014; Shatz, Rogan, Sangermano, Ogneva-Himmelberger, \& Chen, 2013; Trotter \& Hull-Sanders, 2015; Yemshanov et al., 2017). Some of these models describe the potential spread at a large spatial scale, based principally on ALB habitat and tree suitability. These models are helpful for example for management and prevention strategies at the province or country level (adjustment of communication and prevention campaigns, professional education and control of merchandise accompanied by wood packaging material), but are not really usable to optimize the monitoring activities at a local scale during an incursion. Others models are useful to fix monitoring boundaries or to evaluate the infestation risk in the area of an infestation. However, three aspects make many of these models hard to use or unsuitable for a concrete case. (i) They frequently need a large amount of various data to estimate parameters, although the only available and reliable information in a newly discovered outbreak area is often the position of the caught or observed ALB adults and infested trees. (ii) Some models help to delimit the monitored area with a confidence level, in function of the distance to an infested tree, but they do not consider the insect pressure, in other words: the beetle population density at a given location. Indeed, to minimize the ratio cost/chance of success, the intensity and the spatial extent of a survey should be adapted to the ALB population, for example whether only one or 100 exit holes are found on a tree. (iii) Some models are very complex, include many constraints, or their output is difficult to interpret. However, people involved in the management are generally practitioners, and the model output must be easy to read and rapidly and directly usable to support decision-making.

We were confronted with a new ALB infestation in 2014 in Marly (Canton Fribourg, Switzerland; 46 $46^{\prime} 50^{\prime \prime} \mathrm{N}, 7^{\circ} 09^{\prime} 20^{\prime \prime} \mathrm{E}$ ). The infestation was severe, divided into two main spots at a distance of $1.5 \mathrm{~km}$ (North West spot: about 170 adult insects, between 140 and 200 exit holes, and 31 infested trees located in a radius of about $250 \mathrm{~m}$; South East spot: eight adult insects, 65 exit holes and 20 infested trees located in a radius of about $40 \mathrm{~m}$ ). At the time of detection, the beetle colony was estimated to have established at least four generations ago. Realizing that the starting points of all surveys are the field observations of ALB adults and infested trees, we developed a simple approach to "use what we know to find what we don't know." We propose a model with low input requirements, developed from theoretical and empirical studies previously published. The output is a risk map which is easy to interpret. Here, we present the approach and discuss its relevance for the monitoring strategy, regarding three infestations discovered in Switzerland: Marly (discovered in 2014), Winterthur (canton Zürich; $47^{\circ} 30^{\prime} 7^{\prime \prime} \mathrm{N}, 8^{\circ} 45^{\prime} 42^{\prime \prime}$ $\mathrm{E}$, discovered in 2012, about 170 adult insects, 200 exit holes and 22 infested trees located in a radius of about $500 \mathrm{~m}$ ) and Brünisried (canton Fribourg; 46 45'32'N, 7016'44" E, discovered in 2011, six adults insects, eight exit holes and 11 infested trees located in a radius of about $150 \mathrm{~m}$ ).

\section{2 | MATERIALS AND METHODS}

Empirical studies using a mass-mark release and recapture method have shown that the number of recaptured ALB decreases exponentially with increasing distance from the release point (Bancroft \& Smith, 2005; Smith, Bancroft, Li, Gao, \& Teale, 2001; Smith, Tobin, Bancroft, Li, \& Gao, 2004). In other words, the probability of ALB presence decreases exponentially as the distance from the point of origin increases. This typical dispersal function was also demonstrated in a real infestation context (Favaro et al., 2015).

In the field, an exit hole corresponds to the point of origin of one beetle. However, not only finding dispersing beetles but also currently infested trees are important for successful control measures. Thus, we can also assume that, after observing a beetle, the probability to find an infested tree with an exit hole decreases exponentially with distance. The probability to find newly infested trees also decreases with 


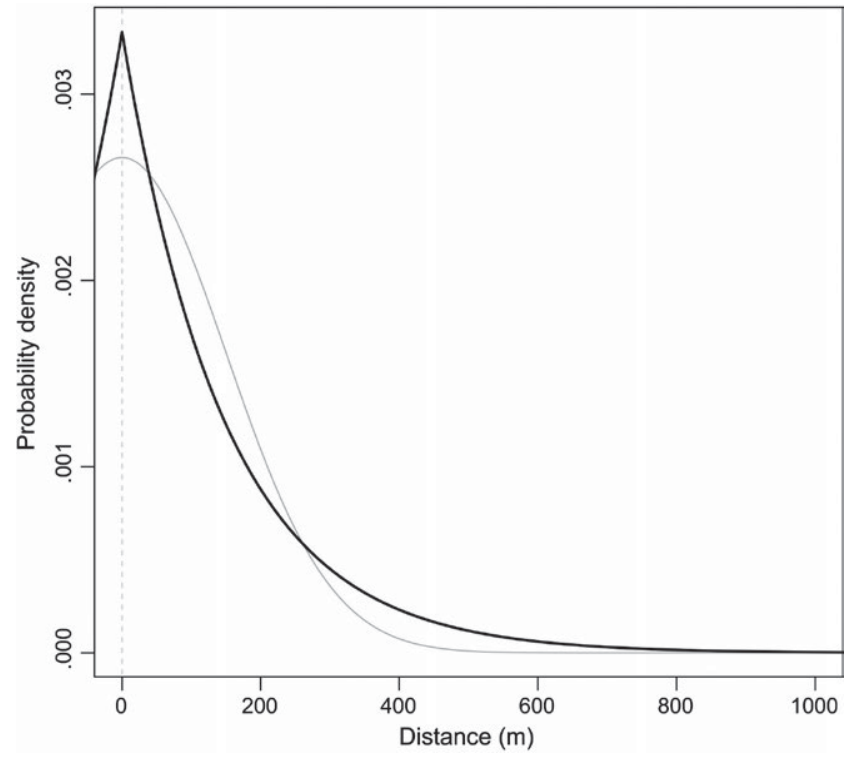

FIGURE 1 The probability density function of the univariate Laplace distribution, $\mathscr{L}(0,150)$ (black line, mean $=0$, scale parameter $=150)$, is compared with the normal distribution $N(0,150)$ (grey line, mean $=0$, standard deviation $\sigma=150$ ). Only the positive range is shown. Heavier tails and the central peak of the Laplace distribution are pertinent to model ALB spread

distance from trees with exit holes or from observed beetles. Finally, when an infested tree is found (observation of oviposition marks, frass from larvae or presence of larvae or eggs in the wood), the probability to find either the adult female that infested the tree or another infested tree similarly decreases with distance.

With our approach, we aim to assess not only the probability of presence of dispersing beetles, but also of infested trees. In other words, the objective is to assess a risk index of the presence of ALB at any life stage, based on field observations.

\section{1 | Required information}

As input in our model, the only information necessary is a list of what we will call O-points. An O-point is a georeferenced point ( $x$-y GPS coordinates, at least $5 \mathrm{~m}$ precision), created according to the following rules:

1. One exit hole leads to one O-point: From this O-point, the probability to find the emerged beetle or newly infested trees decreases exponentially with distance. A tree with 100 exit holes engenders 100 O-points with the same location.

2. One adult ALB leads to one O-point: From this O-point, the probability to find the infested tree where the beetle emerged decreases exponentially with distance. If the beetle is a female, the probability to find newly infested trees also decreases similarly with distance.

3. One infested tree (observation of oviposition marks, frass from larvae or presence of larvae or eggs in the wood) leads to one O-point: From this $\mathrm{O}$-point, the probability to find the female beetle that infested the tree decreases exponentially with distance. The probability to find other trees infested by the same female beetle or the tree where it emerged similarly decreases with distance. In contrast to exit holes, infested trees, even when they contain more than one egg deposition or larvae of ALB, count only as one O-point. However, if it has been ascertained that two or more females infested a tree (for example based on a high number of oviposition marks (>30), genetic analyses of larvae or eggs or if immature stages are of significantly different age), the number of O-points at the same location must then be increased accordingly.

If a beetle is captured directly after emergence and if there is no reasonable doubt that the beetle went somewhere else, the O-point of the beetle and of its corresponding exit hole can be deleted, as there is no more risk with this beetle and this exit hole. More generally, double counting will happen. For example, a found beetle might have emerged from one of the exit holes already counted. But as there is no proof that they are linked, both must be counted. Moreover, if the beetle is a female, other trees could also already have been infested in the meantime. Double counting will generally increase the estimated risk index of finding ALB at a site (see model below) and thus has a conservative effect on recommendations where to monitor for ALB presence (see discussion), in line with the precautionary principle.

In Switzerland, the field observations of ALB (O-points) were firstly recorded when the infestation was discovered. Adult beetles were captured manually and infested trees were rapidly felled, chipped to small pieces $(<3 \mathrm{~cm})$ and burned. However, it is important to collect the data before all the infested material is destroyed. New O-points were then added during the monitoring, when new beetles or infested trees were found. The monitoring was usually carried out twice a year, that is in spring before the flight period and in autumn after the flight period, by tree climbers and detection dogs. The flight period is mainly concentrated between June and August in Switzerland (Wermelinger et al., 2015). We additionally used potted maple trees as trap trees to attract insects in the infested areas. They were checked every week during the flight period. Our experience suggests that the trap trees can be helpful; however, they are probably not very efficient. Only a few ALB were attracted (only three beetles in the first year in Marly on 15 trap trees, but notice that the majority of beetles was already captured before trap trees were installed). After the sanitary felling, the density of surviving adults was fortunately low, so it was difficult to evaluate the effectiveness of the trap trees.

The list of O-points is not fixed. It will grow when new field observations are collected and the corresponding risk map will improve its relevance. The question is how to consider "old O-points" (ancient observations but also new observations of ancient infestations, like old oviposition marks or overgrown exit holes). As ALB's full life cycle normally lasts 2 years in Switzerland, one could recommend to delete O-points that are sure to be more than 2 years old. However, it is not that simple and we think that a generally valid solution does not exist. For example, a newly found ancient exit hole is the evidence that two ALB generations were present at that locality. Although this Opoint is ancient, the area should be considered as potentially infested and a monitoring should be carried out. Such an O-point should not 


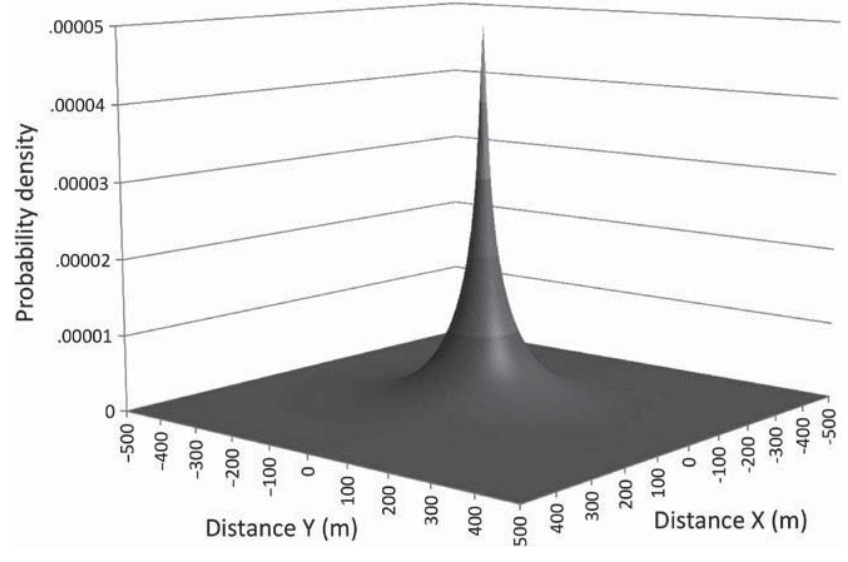

FIGURE 2 Bivariate symmetric Laplace distribution, with the unique scale parameter (standard deviation) $\sigma=150$. The curve is centred here on a $\mathrm{O}$-point located at $(0,0)$

be removed before 4 years of negative survey. We recommend the following procedure: after an analysis of the situation, old O-points should only be removed if they obviously do not contribute to the current population dynamics within the concerned infestation spot anymore. If in doubt, including ancient O-points increases the risk index and thus has a conservative effect on recommendations where to monitor for ALB presence.

\section{2 | Mathematical approach presentation}

As already addressed above, the probability density of ALB presence, as a function of the distance from an O-point, can be modelled by the exponential distribution. The double exponential distribution, better known as the Laplace distribution, seems consequently to be the adequate probability density function choice along one axis (Figure 1). Because of the central limit theorem, the normal distribution is commonly selected to show the spread of independent random variables (i.e., in our case, ALB individuals), when their numbers are sufficiently high (Lyon, 2014). However, the Laplace distribution captures ALB spread better than the normal distribution, because the towering peak of the Laplace distribution at the O-point position accounts for beetles not dispersing from the tree they emerged from (Bancroft \& Smith, 2005; Hull-Sanders, Pepper, Davis, \& Trotter, 2017; Nehme, 2009; Williams, Li, \& Gao, 2004). Commonly, the estimation of the "tail" of the dispersal distribution is a problem in ecology, and the normal distribution may underestimate dispersal if long-distance dispersal occurs frequently (Smith et al., 2001; Turchin, 1997). The Laplace distribution has so-called heavy tails, unlike the normal distribution (Kotz, Kozubowski, \& Podgorski, 2001; Melnick \& Everitt, 2008; Figure 1). This is appropriate for modelling ALB dispersal as some individuals can spread over long distances, in extreme cases more than one or two kilometres, or even more according to flight mill experiments (Smith et al., 2001, 2004; Centre for Agricultural Bioscience International, 2016, Hull-Sanders et al., 2017; Javal, Roux, Roques, \& Sauvard, 2017; Lopez, Hoddle, Francese, Lance, \& Ray, 2017). Moreover, we computed a numerical simulation of ALB spread that reinforces our idea that the Laplace distribution was appropriate (see Appendix S1). In this simulation, we released 1,000 "virtual ALB" from the same point. The different parameters (for example: daily flying distance and lifespan) for every individual were estimated from the literature. The resulting dispersal shows the same pattern as explained above: most of the individuals are concentrated at the release point and their numbers decrease exponentially with distance. Some of them can however reach long dispersal distances (about 400-1,000 m).

As the inputs are lat-long coordinates, we have to consider two spread dimensions. We therefore finally use a bivariate symmetric Laplace distribution $B S \mathscr{L}\left(O_{i}, \sigma_{1}, \sigma_{2}\right)$, where $O_{i}$ is the centre of the distribution (position of the $i^{\text {th }} \mathrm{O}$-point), and where $\sigma_{1}$ and $\sigma_{2}$ are the scale parameters (standard deviations) for the two axes (Kotz, 2002; Kotz et al., 2001). As to our knowledge no study indicates significant preferences in ALB spread along particular cardinal directions, there is no reason to use a Laplace asymmetrical distribution or different scale parameters for the two axes. We consequently assume that $\sigma_{1}=\sigma_{2}=\sigma$.

The probability density function $f$ of the bivariate symmetric Laplace distribution with a unique $\sigma$ is given by

$$
f(x, y)=\frac{1}{\pi \sigma^{2}} K_{0}\left(\sqrt{\frac{2\left(x-O_{x i}\right)^{2}+\left(y-O_{y i}\right)^{2}}{\sigma^{2}}}\right)
$$

for each coordinate $(x, y)$, where $O_{x i}$ and $O_{y i}$ are the coordinates $(x, y)$ of the $i^{\text {th }} \mathrm{O}$-point and where

$$
K_{0}(u)=\frac{1}{2} \int_{0}^{\infty} \frac{1}{t} \exp \left(-t-\frac{u^{2}}{4 t}\right) d t, u>0
$$

The resulting curve has a typical "circus tent" shape and is spatially centred on each O-point (Figure 2).

The total volume below the curve is equal to 1 (total probability of presence) and the volume over a given area represents the probability to find any ALB presence, because of the corresponding O-point. A similar curve must be calculated for each listed O-point.

Lastly, we decided to work at the are-unit scale $\left(1\right.$ are $\left.=10 \times 10 \mathrm{~m}^{2}\right)$. For each square of $10 \times 10 \mathrm{~m}^{2}$, the probability of ALB presence $P_{i}$ (due to $i^{\text {th }}$ O-point) can be determined using the Laplace curve calculated for the $i^{\text {th }} \mathrm{O}$-point, by integrating the volume under the curve for the given $10 \times 10 \mathrm{~m}^{2}$ square. Finally, our risk index $(R I)$ was calculated as follows for each $10 \times 10 \mathrm{~m}^{2}$ :

$$
R I=1-\left(1-P_{1}\right)\left(1-P_{2}\right) \ldots\left(1-P_{n}\right)=1-\prod_{i=1}^{n}\left(1-P_{i}\right)
$$

where $n$ is the total number of O-points.

RI corresponds in a theoretical way to the probability to find at least one ALB presence in a given square of $10 \times 10 \mathrm{~m}^{2}$. In practice, this is not always true because of the model characteristics (double counting possible, lack of undiscovered O-points, etc.). However, RI can be used to prioritize where to search considering the current ALB collected field observations (see discussion). The range of $R$ I goes from 
0 (lower risk) to 1 (higher risk). The calculated $R I$ for each $10 \times 10 \mathrm{~m}^{2}$ square does not consider the land cover. Of course, the landscape is not homogenous and $R I$ is principally relevant for areas containing host trees, especially primary hosts.

The script for calculating $R I$ was coded in R language ( $R$ Development Core Team, 2014) and is available in the Appendix S2. The script automatically produces a table with the central coordinates of each $10 \times 10 \mathrm{~m}^{2}$ square and the corresponding Rl. As the calculation can be quite long, we generally limit the output to a $3 \times 3 \mathrm{~km}$ surface area $\left(90,000\right.$ squares of $\left.10 \times 10 \mathrm{~m}^{2}\right)$. The output can be visualized as map using GIS software.

\section{3 | Parameter estimation}

A single parameter must be assumed in our model, that is the standard deviation $\sigma$ of the bivariate symmetric Laplace distribution. This parameter is similar to the mean in the corresponding exponential distribution. It is possible to find in the literature diverse information about mean ALB spread during one season. It was found in different conditions to be $103.6 \mathrm{~m}$ (Wen, Ye, Li, \& He, 1998), between 192 and $316 \mathrm{~m}$ (Smith et al., 2001), at $129 \mathrm{~m}$ (Bancroft \& Smith, 2001) and our simulation (Appendix S1) gave us a mean dispersal distance of about
$130 \mathrm{~m}$. The local conditions (e.g., density of hosts, weather, presence of natural or artificial barriers and non-natural spread by transport) can have a great impact on the mean dispersal distance. However, there is no reliable possibility to evaluate dispersal in a new infestation. Thus, in the absence of data and to limit and simplify the input requirements, we propose an average standard mean dispersal distance of $150 \mathrm{~m}$ $(\sigma=150)$. Thus, after calculation using the Laplace distribution with $\sigma=150$, the theoretical median spread distance is $103.97 \mathrm{~m}(\sigma \ln (2))$ and the $98 \%$ limit is at about $525 \mathrm{~m}$ from an O-point. The influence of the parameter's value modification is discussed later (see discussion).

\section{4 | Evaluating relevance}

In Marly, a georeferenced dataset of all primary host trees in a radius of about $400 \mathrm{~m}$ around the infestation spots was recorded. Between 2014 and 2016, all of these trees were checked six to eight times by tree climbers and detection dogs. We therefore assume that we know with a good accuracy which trees were infested and which were not. We used this dataset (primary hosts with trunks larger than $3 \mathrm{~cm}$, $n=1,203$, Appendix S3) to compare the true probability of being infested and the RI per $10 \times 10 \mathrm{~m}^{2}$ given by our model at the location of the tree. To investigate this, a generalized linear model (GLM) with

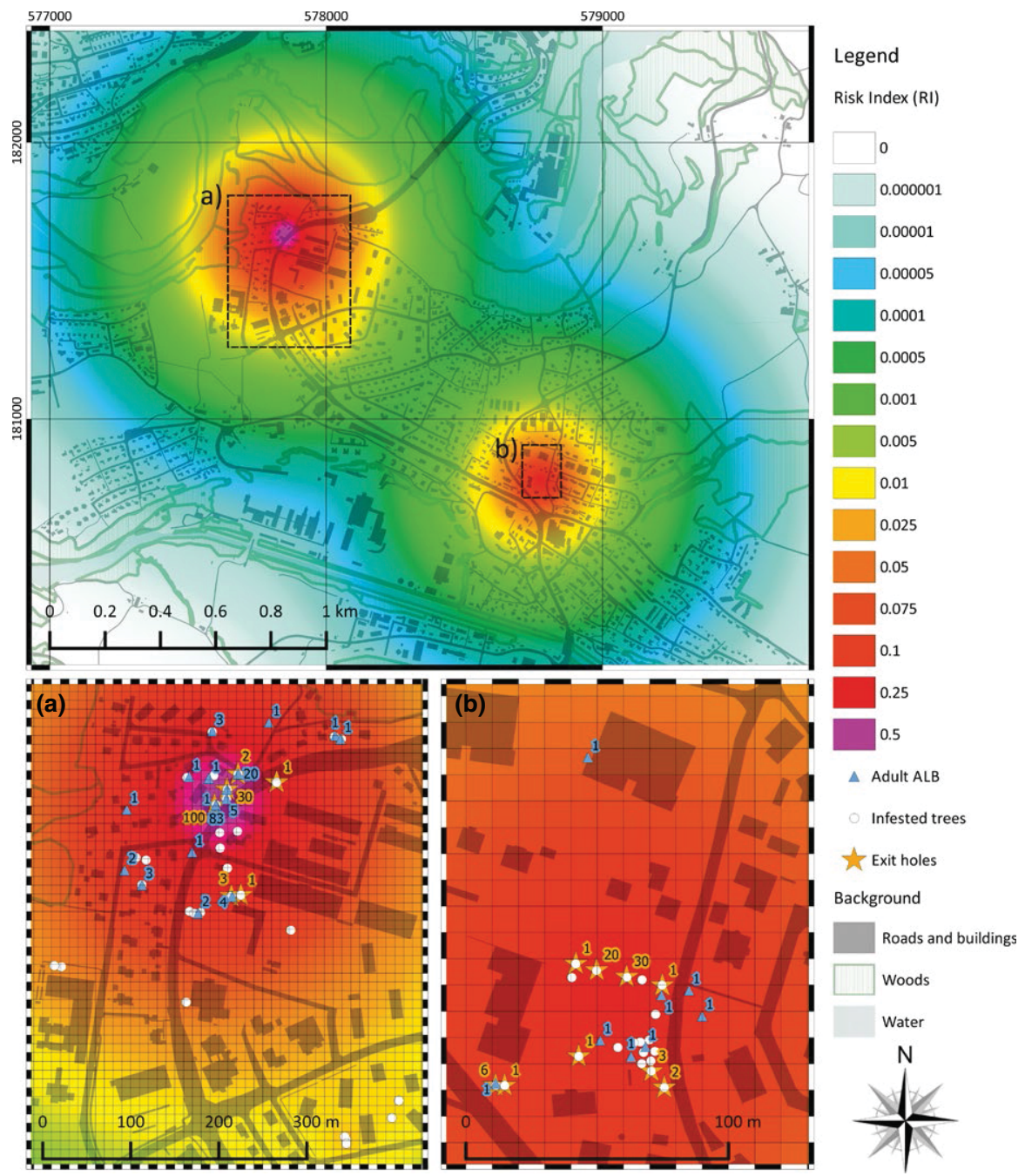

FIGURE 3 Risk map for the Marly infestation (Switzerland). The colour gradient indicates the risk index $(R I)$, from purple $(R I>0.5)$ to white $\left(R I<10^{-6}\right)$. The upper map gives an overall view of the two main infested spots $(X-Y$ Swiss coordinate system, $\mathrm{CH} 1903$ LV03). The areas in the black dashed rectangles a) and b) are zoomed below, with positions of all observed O-points. White dots = position of infested trees (observation of larvae, eggs or oviposition marks); blue triangles = position and number of ALB adults; orange stars $=$ position and number of exit holes 
binomial error distribution and logit link function was used (Dobson, 1990). The goodness of fit of the computed GLM was assessed using Nagelkerke's pseudo R ${ }^{2}$ (Faraway, 2006; Nagelkerke, 1991), and a likelihood ratio test was performed against the null model (Johnson \& Omland, 2004).

\section{3 | RESULTS}

We present in detail the results and the risk map for the Marly infestation (Figure 3). Results and data for two other infestations in Switzerland (Winterthur, Brünisried) are shown in Appendix S4.

The presence of ALB was discovered in Marly in summer 2014. For the present publication, we used in the model all field observations made since the first discovery up to spring 2016. Most of the observations were made during the year 2014 when the first eradication activities took place, and only two infested trap trees were discovered during the monitoring in 2015. Altogether we had a total of 424 O-points. One hundred and 75 of these were ALB adults, 202 were exit holes (fresh and old) observed on 15 different trees and 47 were infested trees (Appendix S5). The O-points are divided into two main infestations $1.5 \mathrm{~km}$ apart. The north-western (NW) spot was the older and more extensive one; here, a total of about 160 ALB adults and heavily infested trees were discovered, for example one with at least 100 exits holes. In the south-eastern (SE) spot, only a few adults were discovered but some infested trees and a moderate number of exit holes were discovered in a circular area of approximately $100 \mathrm{~m}$ diameter (Figure 3). It is not known how the second SE infestation spot in Marly started, but genetic analyses (mitochondrial sequencing) showed that the beetles belong to the same origin as individuals from the older NW spot (Forster \& Hölling, unpublished data). We do not know whether a female flew that far without laying eggs on trees in between, or whether beetles were passively transported by humans, for example with firewood or tree trimming material, or simply hitchhiking on vehicles.

The modelled output risk map highlights this difference between the two infestation spots (Figure 3). The RI was highest close to heavily infested trees with many exit holes and adults in the vicinity. In the NW spot, the tree with 100 exit holes and 83 adults had a great weight in the model and produced the highest risk peak. In the second spot, the two contiguous trees with respectively 30 and 20 exit holes also had a large weight and led to another peak. The other O-points were partially masked by these two risk peaks, but each of them increased $R I$ at their location. A 3D plot helps to visualize small peaks due to other O-points (Figure 4). $R I$ was higher than 0.01 on a larger area in the NW spot $(R I>0.01$ on about 4480 squares of $10 \times 10 \mathrm{~m}^{2}$ (44.8 hectares) in the NE spot and on about 1180 squares of $10 \times 10 \mathrm{~m}^{2}$ (18.8 hectares) in the SE spot) as the insect pressure (number of $O$-points) was much higher and was visibly extended to the south and south-east because of a discovered group of infested trees. No further infestations have been observed yet between the two spots; however, the map indicates that the area was at a certain risk (Figures 3, 4b).
Figure 5 shows, for the Marly infestation, the logistic GLM fit of the calculated $R I$ per $10 \times 10 \mathrm{~m}^{2}$ against infested/uninfested host trees. A squared and a cubic term were added to improve the GLM fit. The terms added were significant according to a Wald test or a likelihood ratio test (Engle, 1984). The Akaike information criterion (Akaike, 1974) was lower when the squared and the cubic term were added in the GLM. According to a likelihood ratio test, the computed GLM (degrees of freedom $=1,199$, residual deviance $=264.8$ ) was significantly different ( $p$-value $<0.0001)$ from the null model (degrees of freedom $=1,202$, residual deviance $=422.2$ ). $R I$ was correlated with the true probability for trees of being infested (Nagelkerke's pseudo $R^{2}=.41$ ), and the model roughly followed the diagonal.

The lowest $R I$ in Marly at the location of an infested primary host was 0.019. Four infested secondary hosts were discovered in the centre of the NW spot, all at locations with very high RI values. The lowest $R I$ at the location of an infested secondary host was 0.356 .

In Winterthur, the infestation was also severe, localized in one extended spot. About 170 ALB adults and 200 exit holes were discovered. Twenty-two trees were listed as infested, including one secondary host near the infestation centre. The lowest $R I$ at the location of an infested primary host was 0.008 and 0.281 at the location of the infested secondary host. Finally, the Brünisried infestation was less severe with only six adults, eight exit holes and 11 primary hosts infested. No secondary hosts were infested; it is however possible that a beetle attempted to lay eggs on a Prunus sp. near the infestation centre. The lowest $R I$ at the location of an infested primary host was 0.006 (Appendix S4).

\section{4 | DISCUSSION}

The risk maps show that our mathematical approach captures the beetle pressure (number of O-points), as shown for the two infested spots in Marly (Figures 3, 4). A high pressure in the NW spot (about 250 O-points in a circle of about $30 \mathrm{~m}$ radius) led to a high $R I$ and on a larger surface compared to the SE spot (about 60 O-points in a $30 \mathrm{~m}$ radius circle). In the NW spot, the dispersal of ALB adults and infested trees was wider, probably linked with higher beetle pressure and age of infestation. It was also previously shown that the risk of ALB spread increases with population size (Favaro et al., 2015). We observed in Switzerland that secondary hosts (e.g., Fraxinus sp., Prunus sp. and Fagus sp.) were infested only where the insect pressure (and consequently RI) was high, as in the NW spot in Marly. As ALB is often not able to complete its life cycle on secondary hosts, it is difficult to understand why some insects sometimes decide to infest such tree species. If no primary host species are in the vicinity, they have of course no other choice. But when primary host species are still present, as in Marly, it is possibly a rare random phenomenon linked with dispersal, which will occur more frequently when the beetle population (insect pressure) is higher. Similar phenomena have been observed in other alien species, for example in the horse chestnut leafminer (Cameraria ohridella) that also oviposits on non-host trees (Acer sp.) when population densities are very high (Péré, Augustin, Turlings, \& Kenis, 2010). 
(a)

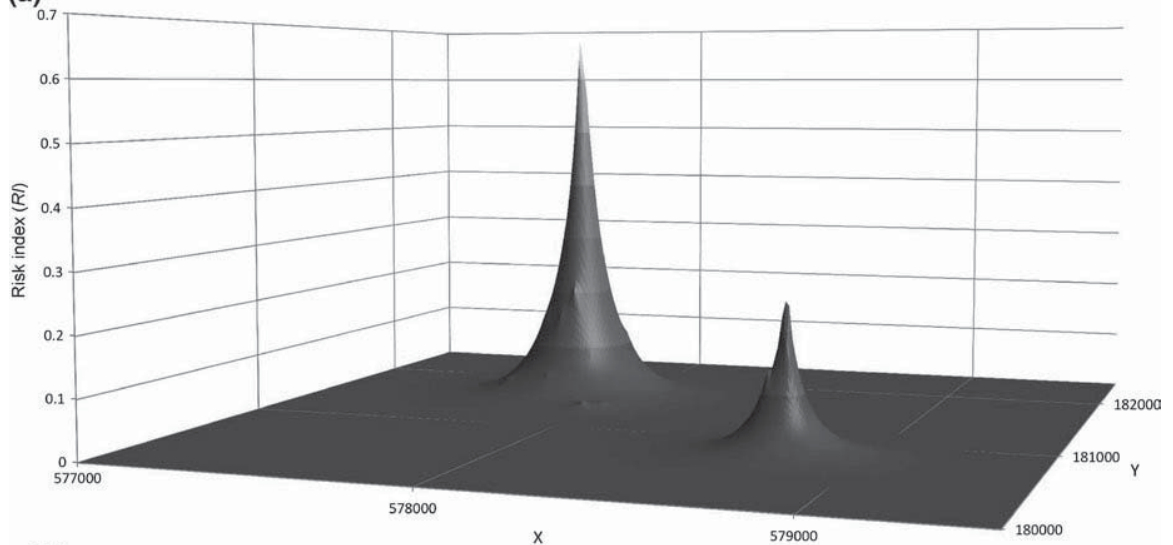

(b)

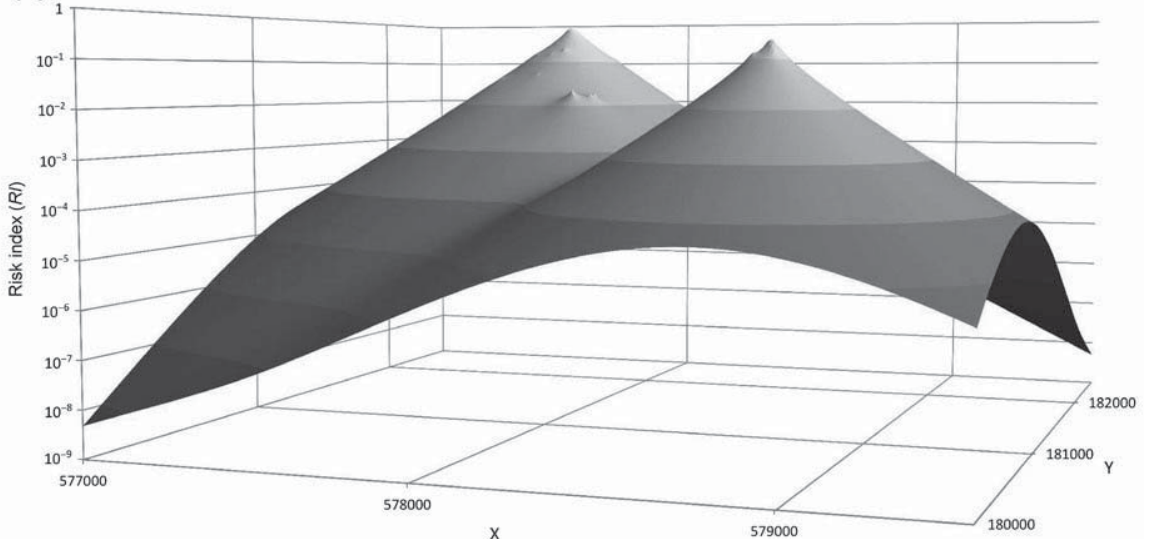

FIGURE 4 3D plot of the risk index (RI), for the Marly infestation (Switzerland). $X$ and $\mathrm{Y}$ in Swiss coordinate system $\mathrm{CH} 1903$ LV03 (1 unit corresponds to 1 metre). a) linear scale, b) logarithmic scale

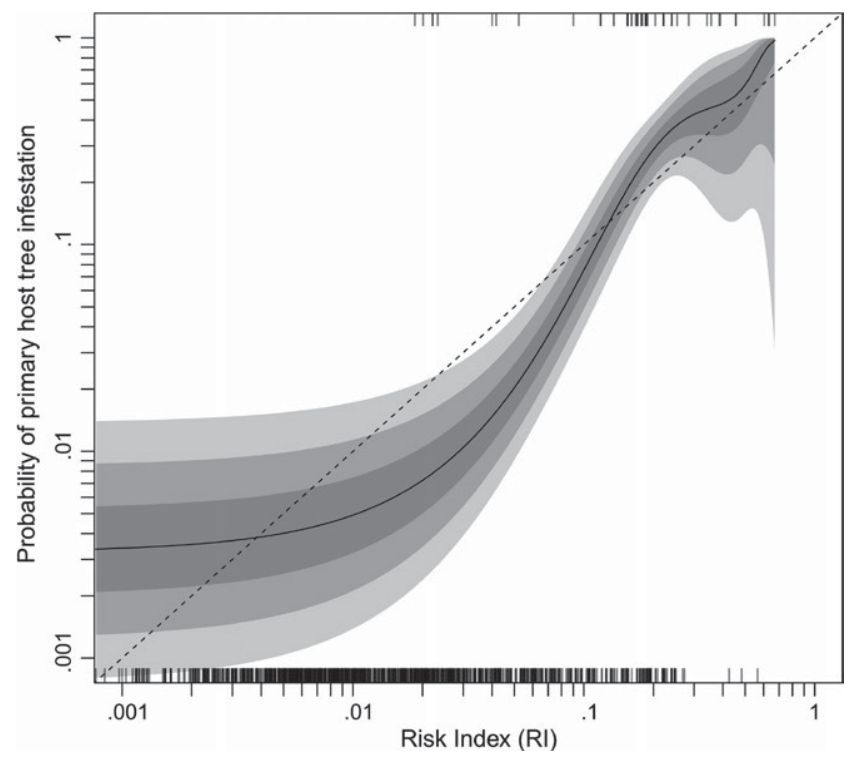

Our study and the risk map highlight that the decision-makers confronted with ALB infestations should take into account the insect pressure to optimize the further monitoring strategy. Commonly, constant distances from the discovered infestations are used to fix survey boundaries (EPPO, European and Mediterranean Plant Protection Organization, 2016; Pluess et al., 2013; USDA, United States Department of Agriculture, 2016), which is not always judicious when the aim is to invest efforts and money cleverly, in order to maximize the chance of success with given means and resources.

Therefore, our risk map can be a useful tool to visualize priorities for monitoring activities in an infestation spot. It can help to design the surveyed zones and to decide which potential host trees should be checked. Considering the RI, we made recommendations about monitoring actions. The proposed approach is compiled in Table 1 and compared with the actual observations in the three analysed Swiss infestations. The thresholds were determined mainly by considering the lowest $R I$ at the location of infested primary and secondary hosts, in the different Swiss infestations. These recommendations and the thresholds stay of course subjective and should be considered as mini5 Logistic generalized linear model (GLM) fit of the calculated risk index $(R I)$ against infested/uninfested host trees $(n=1,203)$, for the Marly infestation (log-log scale). The solid line indicates the GLM fit and the grey areas represent one, two and tree standard errors, respectively. The plot diagonal is shown by the dashed line. The vertical segments indicate for each tree the corresponding $R I$, for uninfested trees (bottom, $n=1,152$ ) and infested trees (top, $n=51$ ) mum recommendations. The extent of the monitoring depends mainly on available means: if funds for ALB eradication are restricted, we suggest following as closely as possible the above recommendations for monitoring. If more extensive means are available, the thresholds can be lowered and thereby the monitoring area and intensity increased 
TAB LE 1 Proposed monitor actions after the calculated risk index $(R I)$ and true presence of attacked primary and secondary hosts in three analysed Swiss infestations in the corresponding RI range

\begin{tabular}{|c|c|c|c|c|c|c|c|}
\hline RI & Proposed monitoring & $\begin{array}{l}\text { Marly } \\
\text { presence of } \\
\text { attacked } \\
\text { primary hosts }\end{array}$ & $\begin{array}{l}\text { Marly presence } \\
\text { of attacked } \\
\text { secondary } \\
\text { hosts }\end{array}$ & $\begin{array}{l}\text { Brünisried } \\
\text { presence } \\
\text { of attacked } \\
\text { primary hosts }\end{array}$ & $\begin{array}{l}\text { Brünisried } \\
\text { presence } \\
\text { of attacked } \\
\text { secondary hosts }\end{array}$ & $\begin{array}{l}\text { Winterthur } \\
\text { presence } \\
\text { of attacked } \\
\text { primary hosts }\end{array}$ & $\begin{array}{l}\text { Winterthur } \\
\text { presence } \\
\text { of attacked } \\
\text { secondary hosts }\end{array}$ \\
\hline$>0.25$ & All broadleaf host trees & Yes & Yes & Yes & $\mathrm{No}^{\mathrm{a}}$ & Yes & Yes \\
\hline $0.25-0.1$ & $\begin{array}{l}\text { All primary hosts, all } \\
\text { secondary hosts (in } \\
\text { particular if lack of } \\
\text { primary ones) }\end{array}$ & Yes & No & Yes & No & Yes & No \\
\hline $0.1-0.01$ & $\begin{array}{l}\text { All primary hosts, } \\
\text { secondary hosts only } \\
\text { if they are attacked in } \\
\text { infestation centre }\end{array}$ & Yes & No & Yes & No & Yes & No \\
\hline $\begin{array}{l}0.01- \\
0.005\end{array}$ & All primary hosts & No & No & Yes & No & Yes & No \\
\hline $\begin{array}{c}0.005- \\
0.001\end{array}$ & $\begin{array}{l}\text { All primary hosts ( } 2 \text { nd } \\
\text { priority, depending on } \\
\text { means) }\end{array}$ & No & No & No & No & No & No \\
\hline$<0.001$ & $\begin{array}{l}\text { Primary hosts, limited } \\
\text { controls in pertinent } \\
\text { zones }\end{array}$ & No & No & No & No & No & No \\
\hline
\end{tabular}

Bold indicates the most important data. ${ }^{a}$ Only unsuccessful egg depositions on Prunus.

for more precaution. However, in any case, we suggest considering the risk map to prioritize the area that should be monitored to keep the cost-benefit balance as good as possible.

In Marly, the RI was correlated with the true probability of primary host trees of being infested (Figure 5); this result is expected considering how the model is built. However, interestingly, the GLM fit was closely following the diagonal, indicating that the RI could provide an approximation of the probability of primary host trees to be infested, when most of the O-points are already known. It would be interesting to also analyse this in other infestations, if similar datasets including all infested and uninfested primary hosts in the infestation area were available. Our method was also not applied to a very large dataset of massive infestations (as occurs for example in some cases in the USA or France), so we cannot say how the model will perform in large outbreaks. However, there is no reason to think that the outcome must be interpreted differently when more O-points are included in the dataset. The difficulty could come with the dataset itself, to keep only relevant O-points of the current ALB population outbreak.

If the normal distribution is used instead of the Laplace distribution (with the same parameter), the risk map is not very different, however, the Laplace distribution has two advantages (graphs 2.1-2.6 in Appendix S6). Firstly, the normal distribution underestimates the risk at the O-point location. For example in Marly, the maximum $R I$ in the highly infested area (250 O-points in a 30 m radius) was only about 0.2 with the normal distribution. It is low in such an area where the insect pressure was very high and where the probability of primary hosts to be infested is very significant. With the Laplace distribution, the maximum $R I$ increases to about 0.7 . The risk of primary host trees to be infested is better captured by the Laplace distribution in those areas, especially where $R I>0.1$. Secondly, the Laplace distribution considers better the risk of rare long dispersal. In Marly, with the Laplace distribution, $R I>0.001$ up to about $600 \mathrm{~m}$ of the centre of the highly infested area (500 $\mathrm{m}$ with the normal distribution) and $R I>0.0001$ up to about $820 \mathrm{~m}$ (600 $\mathrm{m}$ with the normal distribution).

A model is always a simplification of reality, and a good analysis of the field characteristics is necessary to evaluate the pertinence of the RI. The tree distribution and the possible presence of natural or artificial barriers such as cliffs, large open surfaces or buildings must be considered. The dominant wind direction (Hull-Sanders et al., 2017) and the presence of vehicles as vectors could also influence the ALB spread. Decision-makers must anyway also consider these factors when the monitoring strategy is set up.

We proposed a fixed parameter in our model (default value, $\sigma=150$ ). According to the literature and our simulation, this value seems to be a good compromise and simplifies our approach. Nevertheless, in practice, this value can be adapted, for example considering the field characteristics (for example the host trees density). We calculated the risk map with other parameter values $(\sigma=100,200$, 300, graphs 1.1-1.12 in Appendix S6). Overall, a greater value flattens the centre of the curve and thickens the tails. But it is not possible to have a simple procedure to choose the optimal parameter value. In general, we suggest to keep the default value.

The host tree density is one important aspect that can influence the spread of the beetle that is not directly covered by our approach. We avoided to include this parameter because it is very complex to link host density and beetle movement directly, and because it can be very time consuming to collect the data to evaluate it. It probably 
depends of multiple underlying factors, for example the tree species, the tree diameters, the small-scale tree distribution (clustered, scattered), the local beetles' preferences and other geographical and climatic factors. We intuitively suggest, as addressed above, to modify the $\sigma$ parameter if the host tree density is very low (trees very sparse or no trees) or high (for example in a forest containing mostly primary host tree species). We also suggest reading other studies considering this factor (e.g., Favaro et al., 2015).

We chose to give the same weight to each O-point to keep the input requirements simple. We could have for example weighted male and female adult beetles differently, because females can generate new infestations and seem to disperse over larger distances (Bancroft \& Smith, 2005). However, adult males must anyway be considered, as they indicate an infested tree in the surrounding, where they emerged. Moreover, the probability that a male fertilized a female is high in the surrounding area and decreases with distance.

As the risk for undetected satellite infestations in a wider distance may be increasing when an ALB population is present for several generations, sampling within a buffer zone (Pluess et al., 2013) is an accurate method of monitoring preferably combined with adapted public relations (e.g., distribution of flyers to the public). After newly discovered beetle activities, the model can be rerun to keep the risk map up to date. Thus, during an eradication campaign, it is very important to track and record all field observations, which is sometimes neglected in the haste. Our model only needs location data from observed ALB signs, which are reasonably easily gathered with a diligent effort.

Asian longhorned beetle must be surveyed and eradicated by law in many countries to which it is alien. On the occasion of a new discovery of an infestation, a first rough-and-ready description of extent and colonized host trees can be established within a few days. After having this first overlook, our method can be used; means and manpower for surveys like arborists or detection dog teams can be more efficiently organized. People will be able to monitor the most sensitive areas as a priority in order to keep the cost-benefit ratio as good as possible. The risk map is a big help to visualize the area that could be colonized by ALB. Of course, we also recommend consulting other studies cited in this manuscript, to get the maximum information and always work on the best strategy. We assume here to work on a simple and accessible method, but it can be enriched with other approaches, if necessary. We for example recommend the "spatial decision support system" of Fournier and Turgeon (2017) that can help in general organization during the surveillance phase with a loop and re-evaluation procedure. This moreover could be pertinently coupled with our method. Yemshanov et al. (2017) proposed a mathematical approach where they attempt giving a tool to select the best among different strategies to reduce the risk of high costs during a campaign. Other studies considering for example ALB biology and individual movements give valuable information that should be considered.

Our approach was not only used in Marly, but also in two other Swiss infestation spots of Brünisried and Winterthur. Even if all three localities are quite different, the risk maps (Figure 3, Appendix S4) reproduce well the ALB pressure and are in conformity with the recent field detections of ALB individuals or their traces. The risk map is a valuable support tool for the design of the monitoring strategy and helps implementing the Swiss guidelines (Pluess et al., 2013) by providing optimal layouts of the required survey zones. Optimizing the survey strategy is essential to keep a good balance between costs and efficacy for such long periods of monitoring.

The infestation in Winterthur was considered as eradicated in 2016 and the one in Brünisried should also be considered as eradicated at the end of 2017 if no new detections of ALB presence occur. In Marly, no more adult ALB or exit holes were observed in 2015 and 2016, but according to international standards (EPPO, European and Mediterranean Plant Protection Organization, 2016), the monitoring needs to be continued for two beetle generations (usually 4 years). We started using our approach in the year 2015 as a support for planning the monitoring activities. In the infested area, the 2 years of intensive monitoring have provided a trustworthy list of O-points. The resulting risk map is highly pertinent to point out the trees that are most at risk, and where monitoring has to be very thoroughly continued.

\section{AUTHOR CONTRIBUTION}

YF developed the concept, the mathematical approach and wrote the main manuscript. YF, BF and DH collected the data. YF, BF, DH and $\mathrm{SB}$ analysed the results. $\mathrm{YF}, \mathrm{BF}, \mathrm{DH}, \mathrm{BW} \& \mathrm{SB}$ reviewed the manuscript. YF, BF, DH, BW \& SB read and approved the final manuscript.

\section{ACKNOWLEDGEMENTS}

We acknowledge André Chassot of the Phytosanitary Service of Grangeneuve Agricultural Institute of the State of Fribourg and Alain Lambert of the Forest and Fauna Service of the State of Fribourg for their support and Gregor Kozlowski of the University and the Natural History Museum of Fribourg and Heike Lischke of the Swiss Federal Institute of Forest, Snow and Landscape Research (WSL) in Birmensdorf for their advices.

\section{CONFLICT OF INTEREST}

All Authors declare that they have no conflict of interest.

\section{ETHICAL APPROVAL}

This article does not contain any studies with human participants or animals performed by any of the authors.

\section{ORCID}

Y. Fragnière (iD http://orcid.org/0000-0003-4167-379X

B. Wermelinger (ID) http://orcid.org/0000-0003-3235-6741

S. Bacher (iD) http://orcid.org/0000-0001-5147-7165 


\section{REFERENCES}

Akaike, H. (1974). A new look at the statistical model identification. IEEE Transactions on Automatic Control, 19(6), 716-723. https://doi. org/10.1109/TAC.1974.1100705

Bancroft, J.S., \& Smith, M.T. (2001). Modeling dispersal of the Asian longhorned beetle. Proceeding US Department of Agriculture Interagency Research Forum on Gypsy Moth and other Invasive Species, USDA Agricultural Research Service.

Bancroft, J. S., \& Smith, M. T. (2005). Dispersal and influences on movement for Anoplophora glabripennis calculated from individual markrecapture. Entomologia Experimentalis et Applicata, 116, 83-92. https:// doi.org/10.1111/(ISSN)1570-7458

Cavey, J. F., Hoebeke, E. R., Passoa, S., \& Lingafelter, S. W. (1998). A new exotic threat to North American hardwood forests: An Asian longhorned beetle, Anoplophora glabripennis (Motschulsky) (Coleoptera: Cerambycidae). Larval description and diagnosis. Proceedings of the Entomological Society of Washington, 100, 373-381.

Centre for Agricultural Bioscience International (2016). Datasheet: Anoplophora glabripennis (Asian longhorned beetle). Centre for Agricultural Bioscience International, Invasive Species Compendium, Datasheets, maps, images, abstracts and full text on invasive species of the world. Retrieved from http://www.cabi.org/isc/datasheet/5557. [Accessed on 20 October 2016].

Dobson, A. J. (1990). An Introduction to Generalized Linear Models. London, UK: Chapman and Hall. https://doi.org/10.1007/978-1-4899-7252-1

Engle, R. F. (1984). Wald, likelihood ratio and Lagrange multiplier tests. In Z. Giliches, \& M. Intriligator (Eds.), Handbook of Econometrics, Vol. 2 (pp. 775-826). Amsterdam, The Netherlands: Elsevier.

EPPO, European and Mediterranean Plant Protection Organization (2016). EPPO Standards on phytosanitary measures. Retrieved from http://www. eppo.int/STANDARDS/standards.htm. [Accessed on 11 May 2016].

Faccoli, M., Favaro, R., Smith, M. T., \& Wu, J. (2015). Life history of the Asian longhorn beetle Anoplophora glabripennis (Coleoptera Cerambycidae) in southern Europe. Agricultural and Forest Entomology, 17, 188-196. https://doi.org/10.1111/afe.12096

Faraway, J. J. (2006). Extending the linear models with R: Generalized linear, mixed effects and nonparametric regression models. London, UK: Chapman and Hall.

Favaro, R., Wichmann, L., Ravn, H. P., \& Faccoli, M. (2015). Spatial spread and infestation risk assessment in the Asian longhorned beetle, Anoplophora glabripennis. Entomologia Experimentalis et Applicata, 155, 95-101. https://doi.org/10.1111/eea.12292

Forster, B., \& Wermelinger, B. (2012). First records and reproductions of the Asian longhorned beetle Anoplophora glabripennis (Motschulsky) (Coleoptera, Cerambycidae) in Switzerland. Bulletin de la société entomologique Suisse, 85, 267-275.

Fournier, R. E., \& Turgeon, J. J. (2017). Surveillance during monitoring phase of an eradication programme against Anoplophora glabripennis (Motschulsky) guided by a spatial decision support system. Biological Invasions, 19(10), 3013-3035. https://doi.org/10.1007/ s10530-017-1505-2

Gourley, S. A., \& Lou, Y. (2014). A mathematical model for the spatial spread and biocontrol of the Asian longhorned beetle. SIAM Journal on Applied Mathematics, 74(3), 864-884. https://doi.org/10.1137/130939304

Gourley, S. A., \& Zou, X. (2011). A mathematical model for the control and eradication of a wood boring beetle infestation. SIAM Review, 53(2), 321-345. https://doi.org/10.1137/100818510

Haack, R. A., Bauer, L. S., Gao, R., McCarthy, J. J., Miller, D. L., Petrice, T. R., \& Poland, T. M. (2006). Anoplophora glabripennis within-tree distribution, seasonal development, and host suitability in China and Chicago. Great Lakes Entomologist, 39, 169-183.

Haack, R. A., Hérard, F., Sun, J., \& Turgeon, J. J. (2010). Managing invasive populations of Asian longhorned beetle and citrus longhorned beetle:
A worldwide perspective. Annual Review of Entomology, 55, 521-546. https://doi.org/10.1146/annurev-ento-112408-085427

Hérard, F., Ciampitti, M., Maspero, M., Krehan, H., Benker, U., Boegel, C., ... Bialooki, P. (2006). Anoplophora species in Europe: Infestations and management processes. EPPO Bulletin, 36, 470-474. https://doi. org/10.1111/j.1365-2338.2006.01046.x

Hoyer-Tomiczek, U., \& Sauseng, G. (2013). Sniffer dogs to find Anoplophora spp. infested plants. Journal of Entomological and Acarological Research, 45(s1), 10-12.

Hu, J., Angeli, S., Schuetz, S., Luo, Y., \& Hajek, A. E. (2009). Ecology and management of exotic and endemic Asian longhorned beetle Anoplophora glabripennis. Agricultural and Forest Entomology, 11, 359-375. https:// doi.org/10.1111/j.1461-9563.2009.00443.x

Hull-Sanders, H., Pepper, E., Davis, K., \& Trotter, R. T. (2017). Description of an establishment event by the invasive Asian longhorned beetle (Anoplophora glabripennis) in a suburban landscape in the northeastern United States. PLoS ONE, 12(7), e0181655. https://doi.org/10.1371/ journal.pone.0181655

Javal, M., Roques, A., Haran, J., Hérard, F., Keena, M., \& Roux, G. (2017). Complex invasion history of the Asian long-horned beetle: Fifteen years after first detection in Europe. Journal of Pest Science, 17, 1-15.

Javal, M., Roux, M., Roques, A., \& Sauvard, D. (2017). Asian Long-horned Beetle dispersal potential estimated in computer-linked flight mills. Journal of Applied Entomology, 138.

Johnson, J. B., \& Omland, K. S. (2004). Model selection in ecology and evolution. Trends in Ecology \& Evolution, 19, 101-108. https://doi. org/10.1016/j.tree.2003.10.013

Kotz, S. (2002). Which is the Right Laplace? In C. M. Cuadras, J. Fortiana, \& J. A. Rodríguez-Lallena (Eds.), Distributions With Given Marginals and Statistical Modelling (pp. 125-141). Berlin, Germany: Springer Science \& Business Media. https://doi.org/10.1007/978-94-017-0061-0

Kotz, S., Kozubowski, T. J., \& Podgorski, K. (2001). The Laplace distribution and generalizations. Boston, MA: Birkhäuser. https://doi. org/10.1007/978-1-4612-0173-1

Lethmayer, C. (2013). First data on the dispersal and potential spread of Anoplophora spp. Journal of Entomological and Acarological Research, 45(s1), 7.

Lingafelter, S. W., \& Hoebeke, E. R. (2002). Revision of Anoplophora (Coleoptera: Cerambycidae). Washington, DC: Entomological Society of Washington.

Lopez, V. M., Hoddle, M. S., Francese, J. A., Lance, D. R., \& Ray, A. M. (2017). Assessing Flight Potential of the Invasive Asian Longhorned Beetle (Coleoptera: Cerambycidae) With Computerized Flight Mills. Journal of Economic Entomology, 110(3), 1070-1077. https://doi.org/10.1093/ jee/tox046

Lu, J.W.T., \& Russell, G.J. (2005). Modeling the Spread of Asian Longhorned Beetle in New York City. In: K. W. Gottschalk (Ed.) Proceedings, 16th U.S. Department of Agriculture Interagency Research Forum on Gypsy Moth and other invasive Species (pp. 57-60). Annapolis, MD. Gen. Tech. Rep. NE-337. Newtown Square, PA: U.S. Department of Agriculture, Forest Service, Northeastern Research Station.

Lyon, A. (2014). Why are normal distributions normal? British Journal for the Philosophy of Science, 65(3), 621-649. https://doi.org/10.1093/bjps/ axs046

MacLeod, A., Evans, H. F., \& Baker, R. H. A. (2002). An analysis of pest risk from an Asian longhorn beetle (Anoplophora glabripennis) to hardwood trees in the European community. Crop Protection, 21, 635-645. https://doi.org/10.1016/S0261-2194(02)00016-9

Manoukis, N. C., Hall, B., \& Geib, M. S. (2014). A computer model of insect traps in a landscape. Scientific Reports, 4, 7015.

Melnick, E. L., \& Everitt, B. S. (2008). Encyclopedia of Quantitative Risk Analysis and Assessment, Vol. 1. Hoboken, NJ: John Wiley \& Sons. https://doi.org/10.1002/9780470061596 
Meng, P. S., Hoover, K., \& Keena, M. A. (2015). Asian Longhorned Beetle (Coleoptera: Cerambycidae), an Introduced Pest of Maple and Other Hardwood Trees in North America and Europe. Journal of Integrated Pest Management, 6(1), 4.

Milius, S. (1999). Son of long-horned beetles. Science News, 155, 380-382. https://doi.org/10.2307/4011462

Nagelkerke, N. J. D. (1991). A note on a general definition of the coefficient of determination. Biometrika, 78, 691-692. https://doi.org/10.1093/ biomet/78.3.691

Nehme, M.E. (2009). Developing monitoring traps for the Asian longhorned beetle. Dissertation, Pennsylvania State University.

Nowak, D. J., Pasek, J. E., Sequeira, R. A., Crane, D. E., \& Mastro, V. C. (2001). Potential effect of Anoplophora glabripennis (Coleoptera: Cerambycidae) on urban trees in the United States. Journal of Economic Entomology, 94, 116-122. https://doi.org/10.1603/00220493-94.1.116

Péré, C., Augustin, S., Turlings, T. C., \& Kenis, M. (2010). The invasive alien leaf miner Cameraria ohridella and the native tree Acer pseudoplatanus: A fatal attraction? Agricultural and Forest Entomology, 12(2), 151-159.

Pluess, T., Cannon, R., Jarošík, V., Pergl, J., Pyšek, P., \& Bacher, S. (2012). When are eradication campaigns successful? A test of common assumptions. Biological Invasions, 14(7), 1365-1378. https://doi.org/10.1007/ s10530-011-0160-2

Pluess, T., Fürst, E., Raemy, O., Sollberger, K., Klay, A., Forster, B., \& Schwarzwälder, B. (2013). Manuel de gestion du risque dû au Capricorne asiatique (Anoplophora glabripennis), Projet pour essai. Service phytosanitaire fédéral SPF. Retrieved from www.bafu.admin.ch/uv-1314-f. [Accessed on 12 January 2016].

R Development Core Team (2014). R: A language and environment for statistical computing. Vienna, Austria: R Foundation for Statistical Computing.

Sawyer, A.J. (2003). Annotated Categorization of ALB Host Trees (Revised Feb, 2010). USDA-APHIS-PPQ, Otis Plant Protection Laboratory. Retrieved from http://www.uvm.edu/albeetle/hosts.htm. [Accessed on 10 November 2015].

Shatz, A. J., Rogan, J., Sangermano, F., Ogneva-Himmelberger, Y., \& Chen, $H$. (2013). Characterizing the potential distribution of the invasive Asian longhorned beetle (Anoplophora glabripennis) in Worcester County, Massachusetts. Applied Geography, 45, 259-268. https://doi. org/10.1016/j.apgeog.2013.10.002

Smith, M. T., Bancroft, J., Li, G., Gao, R., \& Teale, S. (2001). Dispersal of Anoplophora glabripennis (Cerambycidae). Environmental Entomology, 30(6), 1036-1040. https://doi. org/10.1603/0046-225X-30.6.1036

Smith, M. T., Tobin, P. C., Bancroft, J., Li, G., \& Gao, R. (2004). Dispersal and spatiotemporal dynamics of Asian longhorned beetle (Coleoptera: Cerambycidae) in China. Environmental Entomology, 33(2), 435-442. https://doi.org/10.1603/0046-225X-33.2.435

Smith, M. T., Turgeon, J. T., De Groot, P., \& Gasman, B. (2009). Asian longhorned beetle Anoplophora glabripennis (Motschulsky): Lessons learned and opportunities to improve the process of eradication and management. American Entomologist, 55(1), 21-25. https://doi. org/10.1093/ae/55.1.21a

Trotter, R. T., \& Hull-Sanders, H. M. (2015). Quantifying Dispersal of the Asian longhorned beetle (Anoplophora glabripennis, Coleoptera) with incomplete data and behavioral knowledge. Biological Invasions, 17, 3359-3369. https://doi.org/10.1007/ s10530-015-0961-9

Turchin, P. (1997). Quantitative analysis of movement: Measuring and modeling population redistribution in animals and plants. New York, NY: Sinauer Associates.

USDA, United States Department of Agriculture (2016). Asian Longhorned Beetle. United States Department of Agriculture, Animal and Plant Health Inspection Service. Retrieved from http://www.aphis.usda.gov. [Accessed on 13 November 2016].

Van Der Gaag, D. J., Sinatra, G., Roversi, P. F., Loomans, A., Hérard, F., \& Vukadin, A. (2010). Evaluation of eradication measures against Anoplophora chinensis in early stage infestations in Europe. EPPO Bulletin, 40, 176-187. https://doi. org/10.1111/j.1365-2338.2010.02381.x

Wen, J. B., Ye, G., Li, Z., \& He, M. (1998). Relationship between bark thickness of poplars and damage caused by Anoplophora glabripennis. Hebei Journal of Forestry and Orchard Research, 13, 136-140.

Wermelinger, B., Forster, B., Hölling, D., Pluess, T., Raemy, O., \& Klay, A. (2015). Espèces invasives de capricornes provenant d'Asie. Ecologie et gestion. 2e éd. révisée, Notice pour le praticien N50. Birmensdorf, Switzerland: WSL.

Williams, D. W., Li, G., \& Gao, R. (2004). Tracking movements of individual Anoplophora glabripennis (Coleoptera: Cerambycidae) adults: Application of harmonic radar. Environmental Entomology, 33, 644-649. https://doi.org/10.1603/0046-225X-33.3.644

Yemshanov, D., Haight, R. G., Koch, F. H., Venette, R., Studens, K., Fournier, R. E., ... Turgeon, J. J. (2017). A safety rule approach to surveillance and eradication of biological invasions. PLoS ONE, 12(7), e0181482. https:// doi.org/10.1371/journal.pone.0181482

\section{SUPPORTING INFORMATION}

Additional Supporting Information may be found online in the supporting information tab for this article. 